\title{
Modeling spontaneous activity across an excitable epithelium: support for a coordination scenario of early neural evolution
}

\author{
Oltman O de Wiljes ${ }^{1 *}$, Ronald AJ van Elburg ${ }^{2}$, Michael Biehl ${ }^{3}$, Fred A Keijzer ${ }^{1}$ \\ From 24th Annual Computational Neuroscience Meeting: CNS*2015 \\ Prague, Czech Republic. 18-23 July 2015
}

The reason why nervous systems first arose is an open question. Internal coordination models hold that nervous systems evolved initially as a device to coordinate internal activity, enabling multicellular effectors. They stress the use of multicellular contractility as an effector for motility: some sort of coordinative structure would have been necessary to have multicellular effectors in the first place. A recent example of such a model, the skin brain thesis, suggests that excitable epithelia using chemical signaling are a potential candidate as a nervous system precursor.

We developed a computational model and a measure for whole body coordination to investigate the coordinative properties of such excitable epithelia. Using this measure we show that excitable epithelia can spontaneously exhibit body-scale patterns of activation (see Figure 1.). Relevant factors determining the extent of patterning are the noise level for exocytosis, relative body dimensions, and body size. In smaller bodies whole-body coordination emerges from cellular excitability and bidirectional excitatory transmission alone.

Our results show that basic internal coordination as proposed by the skin brain thesis could have arisen in this potential nervous system precursor, providing support that this configuration may have played a role as a protoneural system and requires further investigation.

\section{Authors' details}

'Department of Theoretical Philosophy, Groningen University, Groningen, the Netherlands. ${ }^{2}$ Institute of Artificial Intelligence, Groningen University,

\footnotetext{
* Correspondence: o.o.de.wiljes@rug.nl

'Department of Theoretical Philosophy, Groningen University, Groningen, the Netherlands

Full list of author information is available at the end of the article
}

Groningen, the Netherlands. ${ }^{3}$ Johann Bernoulli Institute for Mathematics and Computer Science, Groningen University, Groningen, the Netherlands.

Published: 18 December 2015

doi:10.1186/1471-2202-16-S1-P120

Cite this article as: de Wiljes et al:: Modeling spontaneous activity across an excitable epithelium: support for a coordination scenario of early neural evolution. BMC Neuroscience 2015 16(Suppl 1):P120.
Submit your next manuscript to BioMed Central and take full advantage of:

- Convenient online submission

- Thorough peer review

- No space constraints or color figure charges

- Immediate publication on acceptance

- Inclusion in PubMed, CAS, Scopus and Google Scholar

- Research which is freely available for redistribution

Submit your manuscript at www.biomedcentral.com/submit
C Biomed Central 


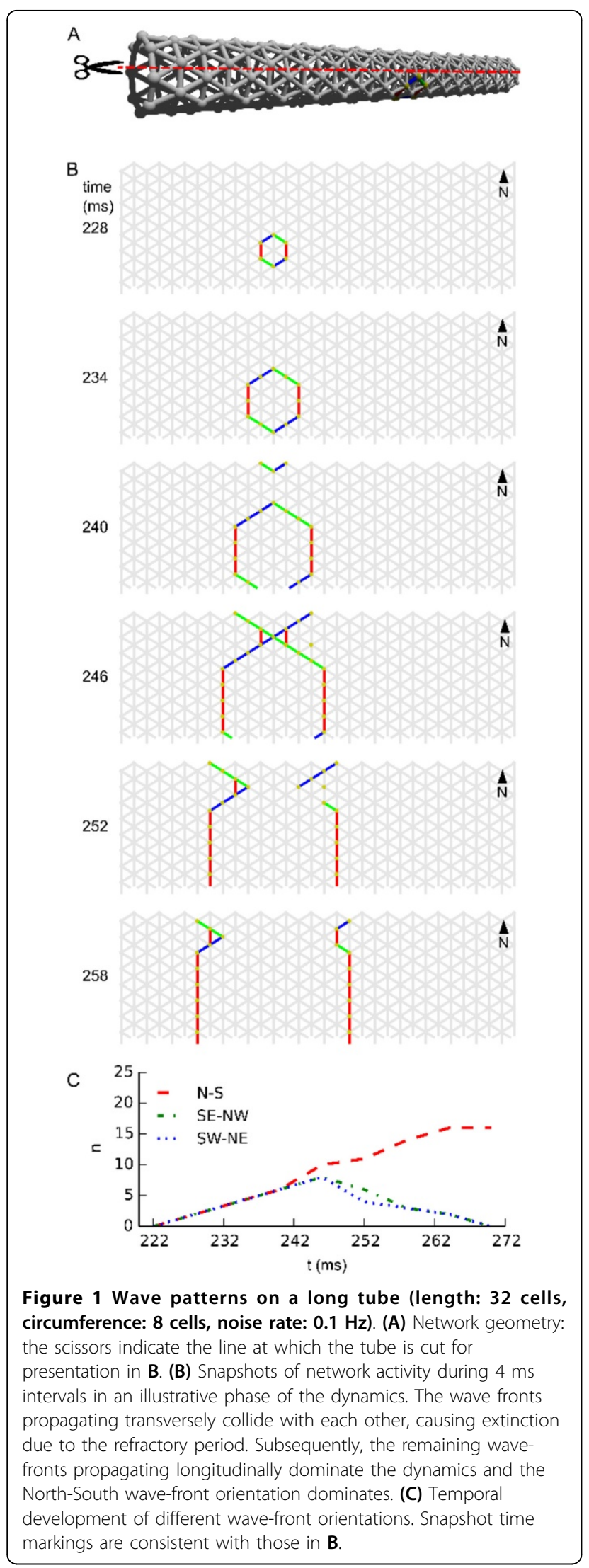

